\title{
Key failure factors of start-up women owned SMEs in service sector in Kigali: a principal component analysis approach
}

\author{
Romain Kasema \\ Atlantic International University, Honolulu, Hawaii, USA
}

Key failure factors of startup women

Received 12 July 2021

Revised 27 August 2021 3 October 2021

Accepted 4 October 2021

\begin{abstract}
Purpose - This study aims to develop and test a framework for studying the failure of new women entrepreneurs in the small- and medium-sized enterprises (SMEs) sector.

Design/methodology/approach - Using a sample of 114 unsuccessful entrepreneurs in Kigali, Rwanda, this study aimed to identify key failure factors of women-owned SMEs. This study used mixed methods where quantitative data were analysed using the principal component approach with Varimax rotation to reduce the variables to only three clusters.

Findings - The study findings revealed that the failure of women-owned SMEs results from the entrepreneur's inability followed by the enterprise incompetence, which are both internally controllable factors and the inauspicious business environment. These findings contribute to the validity of the dynamic capability theory by explaining how well internal and external factors must stay glued together to avoid failure among women-owned SMEs, something that was not yet previously well documented so far.

Originality/value - New SMEs are considered a noteworthy constituent of Rwandan development. Unfortunately, most new SMEs, in general, do not grow; their failure rate is high $(70 \%)$, which raised many worries for both researchers and policymakers as to why this occurs at this stage of business growth Therefore, to the best of the authors' knowledge this paper is the first to analyse the reasons for the failure of Rwandan women-owned SMEs in the service sector. These findings are important because they suggest that policies designed to reduce the incidence of SMEs' failure should take account of the two main factors influencing failure among women entrepreneurs.
\end{abstract}

Keywords SMEs, Failure, Principal component analysis, Women entrepreneurs

Paper type Research paper

\section{Introduction}

Several decades before, the African woman was considered as a nurturer and only attached to household activities. Today, in the face of socioeconomic challenges, women are increasingly freeing themselves from this grip and are now in politics and others in the business. In the context of Rwanda, where women are increasingly performing well in different leadership positions, especially in politics and in public administration, one may wonder if the same goes for women in business.

(C) Romain Kasema. Published in Vilakshan - XIMB Journal of Management. Published by Emerald Publishing Limited. This article is published under the Creative Commons Attribution (CC BY 4.0) licence. Anyone may reproduce, distribute, translate and create derivative works of this article (for both commercial and non-commercial purposes), subject to full attribution to the original publication and authors. The full terms of this licence maybe seen at http://creativecommons.org/licences/by/4.0/ legalcode

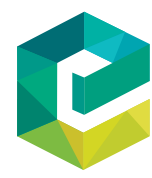

Vilakshan - XIMB Journal of Management Emerald Publishing Limited 0973-1954 DOI 10.1108/XJM-07-2021-0193 
As there are not enough rooms to accommodate all women in politics and administrative positions, women are present in the business, especially in the small- and medium-sized enterprises (SMEs) sector. The SME sector is important for achieving the growth and employment targets of a nation, as they provide employment opportunities and increase national revenue and contribute to productivity and entrepreneur training (Erdin and Ozkaya, 2020). This is relevant in less developed countries such as Rwanda, with serious problems of employment and poverty. In consideration of this importance, several governments over the world have invested much more in the sustainability of this sector. However, the sector is vulnerable to several risks than in large counterparts, limiting it to grow as expected as most SMEs fail in their first year of start-up and rarely $30 \%$ can celebrate their tenth anniversary (Bhole, 2020).

For a time, Rwanda has heavily invested in the elaboration of conducive policies; as a result, the country has been ranked second in Africa for having a good environment in doing business and 29th in the world (World Bank, 2019). Following this conducive business environment, Rwanda registers an average of 10,000 new companies each year (Kasema, 2020). However, despite the growing number of registered new firms in general and Kigali in particular, the number of failed SMEs is too high and alarming in such a way that $80 \%$ of new firms never celebrate their very first anniversary, $50 \%$ never celebrate their fifth birthday and only 10\% can celebrate in their tenth year (RGB, 2012; MINICOM, NISR, MIFOTRI, PSF, 2017). This situation has caused great concern in both academic and policymaker spheres, as a productive economy relies on the creation of new enterprises and their growth. Ironically, despite the widely shared recognition of the importance of SMEs in the Rwandan economy, too little is known about the key factors of business failure in Rwanda, with one noticeable exception of Twesige et al. (2020). Since the factors of failure are common to all economic operators in the SME sector, the choice of women-led SMEs was mainly motivated by their entrepreneurial motivation, which makes them riskier than men. Although men focus on opening new opportunities, women focus instead on achieving a particular goal, in the majority of cases, job frustration and changing personal circumstances (Majiláth et al., 2019). In this context, the results of this study will help policymakers in Rwanda and other countries sharing the same economic conditions to develop reasonable planning to take advantage of SME development, especially those led by women.

The remainder of this paper is structured as follows: the literature review is presented in Section 2, followed by research methodology in Section 3. Although Section 4 reported the results of the analysis and discussion of the same, Section 5 provides a conclusion and recommendations.

\section{Literature review}

\subsection{Theoretical frame}

Synonymous with bankruptcy, SME's failure is an ineffective outcome caused by any factors that are managerially and/or not managerially controllable by the entrepreneur. Although the entrepreneurship literature suggests several causes of business failure, perhaps the most common is based on the inability to run a business. It appears that entrepreneurs with more skills have the knowledge to perform the roles and tasks necessary for success more effectively. This importance is reflected in the considerable attention paid to developing the capability of SMEs, which is in turn anchored in the dynamic capability theory (DCT) on which this study is grounded. In this regard, the DCT provides a useful explanation of the heterogeneity of firm performance based on capabilities rather than on resources availability. It explains why do some firms succeed whereas others fail while in the same business environment, and consider an interaction between the individual- 
company (internal) and environmental (external) factors to determine the success or failure rate (Amankwah-Amoah et al., 2020). However, in the light of DCT, how long the internal and external factors stay glued together to avoid failure among women-owned SMEs is not yet well documented so far, leading to a poor understanding of the varied needs of SMEs at each stage of its growth process. As such, failure has its origins, either internal (explicitly linked to the entrepreneur and the firm) or external to the firm (beyond its control) (Shephered et al., 2019).

Tracking back the causes of failure in the internal and external environment of the organisation leads to the recognition of the two perspectives of failure as presented in the literature: the voluntarist perspective and the deterministic perspective. The voluntarist perspective considers failure as originated from the entrepreneur him/herself, i.e. his/her inability to adequately match resources to changing environment (Barney, 1991; Micelotta et al., 2017). Although the deterministic perspective whose scholars like Swaminathan (1996) and Kücher et al. (2020) consider that failure is imposed by factors that cannot be controlled by the company and the entrepreneur. Whatever the origin of the failure, the factors may vary from one economy to another, depending on the dissimilarity in the economic condition, political and social environment of a country (Arasti, 2011).

A critical review of the literature suggests that scholars are not in agreement about a universal list of factors of failure, making it difficult to overcome the issue of failure universally common. However, the literature confirmed that the main causes of failure fall into three broad categories: firm inadequacy/incompetence, entrepreneur incapacity and bad external environment Mayr et al., 2017; Nikolić et al., 2019; Milosevic et al. (2019). These broad variables have, in turn, some regularly mentioned factors that should be considered not as failure itself but as warning signs that need to be avoided if an SME wants to survive. As a result, an SME can go bankrupt due to a mixture of factors and rarely for one single factor to be involved (European Federation of Accountants (FEE), 2004).

2.1.1 Firm-specific factors. These are variables related to the firm's competency or management deficiency to adapt to the business environment (Bouazza et al., 2015; Amankwah-Amoah, 2016; Bushe, 2019; Chineam et al., 2020). These factors are found within the firm and are managerially controllable.

Among the most cited factors in this variable include poor business planning and management incompetence (Schaefer, 2019; Dento, 2020); the inadequate business location has its implication for access to markets and other resources (Sherman and Seidel, 2019) and management incompetence (Schaefer, 2019). Bushe (2019) recognized the necessity to employ the right people at the right time and with the right skills. DiScipio (2017) and McDonald (2019) showed the importance of customer relationships in marketing. Thus, failing to pay attention and understand the behaviour of customers affects the profitability of most SMEs.

2.1.2 Entrepreneur-specific factors. These are internal variables that relate to the entrepreneur/manager's characteristics and inability to adequately match resources to changing environment (Micelotta et al., 2017). Most entrepreneurs of SMEs do not possess the requisite skill to manage the business; as a result of this, many SMEs have collapsed because their owners do not have the skills to see the future and manage their business properly (Lotich, 2019). The most cited entrepreneur's related factors in the literature include the lack of entrepreneurial skills and business experience, unpreparedness, imitability, imperfect judgement, innovation and perseverance (Bushe, 2019). For instance, according to Abdul (2018), managers of SMEs with entrepreneurial skills are able to generate growth, wealth and well-being by calculating the risk a head of time and secure the sustainability of the firm. In the same vein, Kulkarni et al. (2020) asserted that the growth and development of start-ups are influenced by the experience of founders and their managerial skill sets. 
2.1.3 Environment-specific factors. Also called systemic variables, these are exogenous factors found outside the firm that are managerially uncontrollable by new SMEs (Kücher et al., 2020). Therefore, the failure of the SME often depends on the management's inability to deal with them anticipatively and sufficiently (Stoeberl et al., 1998). They include inadequate economic environment, market competition, inadequate funding system to SMEs needs, high tax, poor infrastructure, insufficient government policies and globalisation (Stoeberl et al., 1998; Nangoli et al., 2013; Bushe, 2019; Abubakar and Junaidu, 2019). For instance, according to Carter (2019), the failure of many SMEs is a result of inadequate financing; most owners of SMEs use their own savings or family and relatives' resources to start the business.

\subsection{Empirical studies}

Numerous empirical studies have been conducted to identify the main reasons for bankruptcy but with mixed results, generally because of the context in which the study was conducted, as stressed by Arasti (2011). For instance, Bushe (2019) studied the causes and the impact of business failure among small and micro and medium enterprises in South Africa and concluded that a firm could get bankruptcy due primarily to the inability of the entrepreneur, followed by the environmental inauspiciousness and finally the incompetence of the firm.

Chineam et al. (2020) examined the main causes of business failure in an empirical study in Nigeria. Data were collected through interviews with 15 entrepreneurs who closed their businesses after operating for at least 4 years. The findings revealed that a firm could fail because of enterprise incompetence, or yet management deficiency such as lack of finance, inadequate economic environment and insufficient government policies were also mentioned as main causes of business failure.

A study by Dento (2020) examined the reasons for the failure of small businesses in Liberia. A survey questionnaire was used to collect raw data. The study revealed the top five contributing factors, including poor business planning, lack of entrepreneurial skills, lack of customer relationship, management incompetence and inadequate financing.

A study by Abubakar and Junaidu (2019) investigated the relationship between environmental factors and the failure of SMEs in the Kano metropolis. A survey instrument was used to collect data from a sample of failed SMEs and analysed using multiple regression and descriptive techniques. The study concluded that a business could fail because of an unconducive business environment such as inadequate infrastructure, market competition, market demography and financial inadequacy.

Milosevic et al. (2019) conducted a study aiming to provide empirical clarification over some key failure factors of SMEs in the Republic of Serbia and Visegrad countries. Data were collected through a survey questionnaire and analysed using the SME with multigroup confirmatory factor analysis for comparative measurement on the observed data. The results pointed out that entrepreneurs are still turning to themselves as the main factors influencing unsuccessful businesses.

A study by Navandar et al. (2021) compared failure factors between private and government construction firms in India. A total of 60 construction firms were selected in and around the Nashik region for the investigation, and data were analysed using a simple multi-attribute rating technique. The findings revealed that lack of experience is the major factor of failure of the business against lack of managerial experience for government construction firms.

To date, the literature has rarely empirically and comprehensively examined the reasons for the failure of women-owned start-up SMEs with an emphasis on unsuccessful firms. In an effort to fill this research gap, this paper contributes to the existing literature by analysing the failure of women-owned SMEs in a female-dominated sector (services) in 
Rwanda, a country with more women in administration and politics, further validating the DCT on which this study is based.

Key failure factors of startup women

\section{Research methodology}

This research study was conducted under an explanatory sequential research design, and both quantitative and qualitative methods were used in collecting data. Qualitatively, data were collected through semi-structured interviews with 11 entrepreneurs who closed their business after at least 3 years of operations, from whom 19 key factors were identified. These 11 entrepreneurs were selected based on convenience and judgemental sampling as they were easily joinable by the researcher and were willing to participate in this study. This study targeted women owners/ managers of failed SMEs established in Kigali city. However, because there is no database from which to determine the population of failed SMEs, the snowball sampling method was used to establish a final sample size across a reference line, where an existing respondent directs the researcher to another potential respondent (Yin, 2011).

Therefore, available participants were surveyed and asked to recommend other women entrepreneurs who met the criteria required for this study, such as being a manager or owner of an SME that has been and operational for not longer than 36 months in the field of hair salon, restaurants, hardware shops, pharmacy, cosmetics and beauty products shops, liquors shops, general trading, stationery and handicraft shops. Kline (2015) recommends a minimum sample size of 1:10 ratio, which resulted in a sample size of 190 participants in consideration of the 19 questions involved in the survey instrument, but 132 were reached. A Likert-type scale questionnaire was used, ranging from $1=$ to a very small extent to $5=$ to a large extent. A response rate of $114(88.6 \%)$ out of the 132 questionnaires distributed was recorded, constituting the final sample size for this study.

The principal component analysis (PCA) with the social science statistical package (SPSS) version 25.0 was used to analyse the collected data. This data reduction technique seeks to reduce a large number of variables to a smaller set of underlying factors that summarise the essential information contained in the variables (Yong and Pearce, 2013; Penkova, 2017).

\section{Results and discussion}

\subsection{Principal component analysis}

To ensure the use of PCA, certain assumptions must be met, such as the sample size, the normality of data, data outliers and missing values. A minimum sample size of 100 subjects is acceptable (Kasema, 2020); this study used 114 respondents. The normality of data was assumed using the Kolmogorov-Smirnov test, whose significance value was respectively $(0.209,0.108$ and 0.789$)$ for each construct; greater than 0.05 (Pallant, 2016), confirming that data were normally distributed. The standard score of KMO exists between 0.5 and 1 , and Bartlett's test of sphericity tests (BTS) the null hypothesis that all variables are uncorrelated (Pallant, 2013). The BTS at 985.216 and the level of significance at $p=0.00$ indicated that the data were suitable for the purpose of PCA while the KMO measure of sampling adequacy was 0.759 (Table 1), which also indicated that there are sufficient items for each factor, supporting the applicability of the PCA technique. Long before, missing values were checked through Little's test, which showed that there was only one case of missing values, and the pairwise deletion method (Hair et al., 2017) was used. In addition, all data passed the outliers test by returning a maximum Mahalanobis distance of 9.6, which was lower than the maximum threshold distance of $X^{2}(2)=11.86, p<0.001$ (Tabachnick and Fidell, 2013). 
The PCA involves the use of the Varimax orthogonal rotation method developed by Kaiser (1958), where Kaiser's criterion of Eigenvalues greater than one and the scree plot for factor's extraction were used. Although Table 2 reported the results of factor's extraction based on the Eigenvalues greater than one criterion; the cut off for the factor load (rotated component matrix) was set at 0.30 (Table 3) as suggested by Hair et al. (2016) for a sample size of 114 which resulted into the identification of three factors.

The results (Table 2) suggest that three components with an eigenvalue greater than one account for $71.412 \%$ of the total variance. A single factor explained $35.9 \%$ of total variance explained, which is smaller than 50\% (Khan et al., 2020). The three identified factors are by order of importance entrepreneur-specific factor with $38.9 \%$ followed by, firm-specific factors with $20.6 \%$ and lastly environment-specific factors (11.7\%) are briefly discussed in the following section.

\begin{tabular}{|c|c|c|}
\hline \multicolumn{3}{|c|}{ KMO and Bartlett's test } \\
\hline Kaiser-Meyer-Olkin measu & lacy & 0.759 \\
\hline Bartlett's test of sphericity & $\begin{array}{l}\text { Approximately Chi-square } \\
\text { df } \\
\text { Sig. }\end{array}$ & $\begin{array}{c}985.216 \\
171 \\
0.000\end{array}$ \\
\hline
\end{tabular}

Note: SPSS output, 2021

Table 1.

$\mathrm{KMO}$ and Bartlett's test for key factors of new women-owned SMEs



Table 2.

Total variance explained

Notes: Extraction method: principal component analysis 


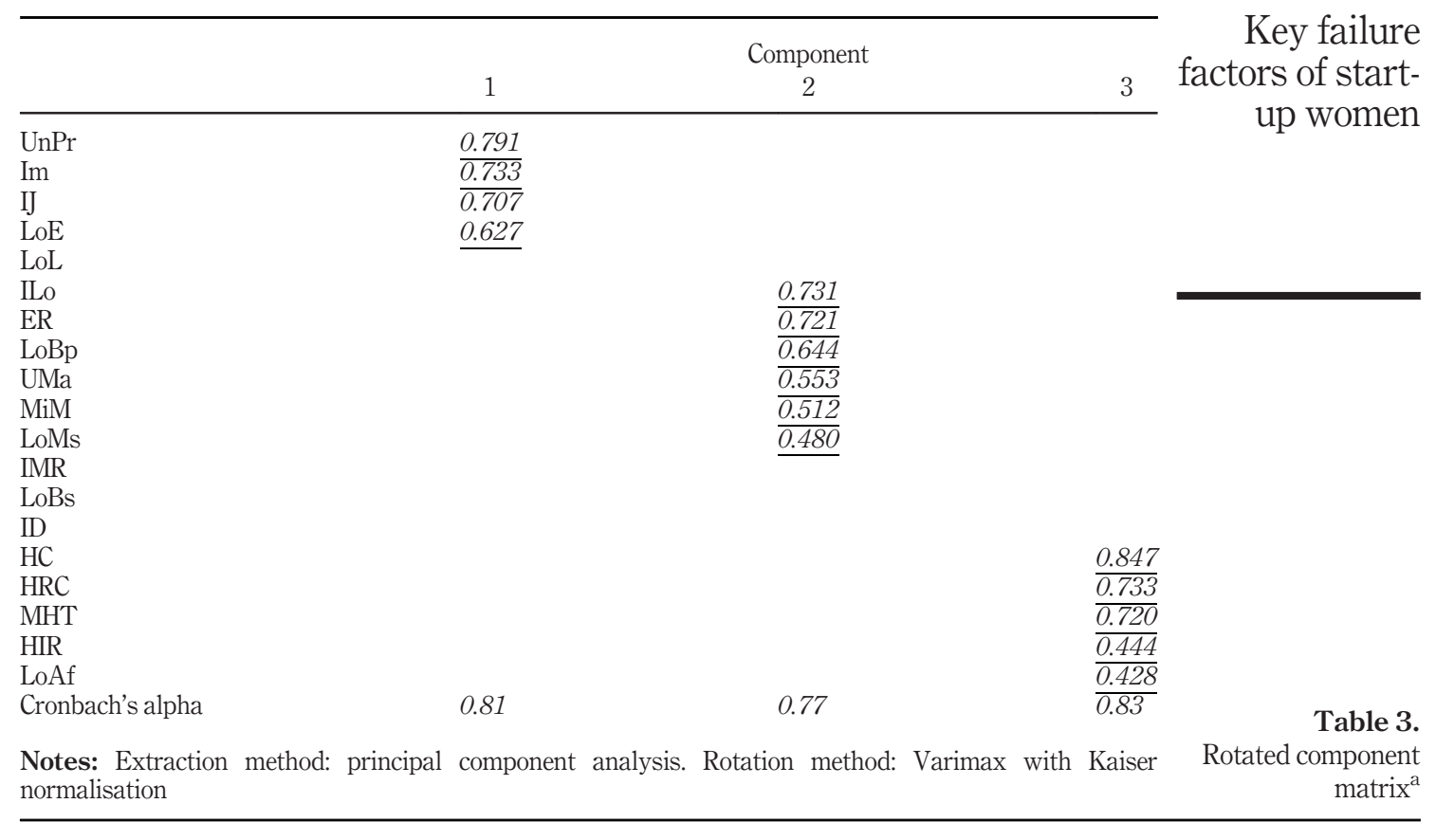

\subsection{Discussion of results}

The first component labelled as "Entrepreneur-specific factors" managerially controllable has an eigenvalue of 7.4 and a percentage of the variance of $38.9 \%$ and consists of four items. This component included factors such as the unpreparedness $(0.791)$ of the owner, imitability (0.733), imperfect judgment (0.707) and lack of business experience (0.627). The lack of leadership was excluded in this model as it loaded poorly $<0.3$ (Hair et al., 2016). The Cronbach value for this component was 0.81, greater than 0.7, indicating the reliability of the construct (Hair et al., 2017). These findings corroborated numerous empirical studies such as Bouazza et al. (2015), Milosevic et al. (2019), Lotich (2019), Bushe (2019), Kulkarni et al. (2020) and Navandar et al. (2021).

The second component labelled as "Firm-specific factors" that are also managerially controllable has an eigenvalue of 3.923, and the percentage of the variance of $20.6 \%$ consisted of six items. These include by order of importance inadequate business location (0.731), employing relatives (0.721), lack of business plan (0.644), unfamiliarity with the market/industry (0.553), mismanagement (0.512) and lack of marketing strategy (0.480). The lack of business skills, inadequate demand and inadequate market research was poorly loaded $<0.3$ (Hair et al., 2016). With a Cronbach's alpha of 0.77 greater than 0.7 , the reliability of the five items constituting this component was assured. Previous empirical studies have also supported these findings (Bouazza et al., 2015; Amankwah-Amoah, 2016; Milosevic et al., 2019; Bushe, 2019; Schaefer, 2019; Chineam et al., 2020; Dento, 2020).

The last component is labelled as "Environment-specific factors," which are external to the business and managerially uncontrollable, has an Eigenvalue of 2.237, and a percentage of the variance of $11.775 \%$ consisted of five items. These include fierce competition ( 0.847$)$, high rent charges (0.733), multiple and high taxes $(0.720)$, high interest rate $(0.444)$ and lack of financing for growth (0.428). The Cronbach's alpha for this component was 0.83 greater 
than 0.7, indicating that the reliability of the items of this component was confirmed. These findings concur with those of Stoeberl et al. (1998), Nangoli et al. (2013), Bushe (2019), Milosevic et al., 2019; Abubakar and Junaidu (2019).

Although the insufficient ability of the owner and incompetence of the firm constitutes the internal factors, the environmental issues related to external factors, in particular, a firm's inability to adapt to its environment. The theoretical implications are that business failure is likely to occur when there is a misalignment between the resources/capabilities of the firm and the environmental demands. As such, the failure of women-owned SMEs is explained in general by low know-how to deploy available rare and inimitable resources/ capability to cope with the changing environment (Barney, 1991; Micelotta et al., 2017; Amankwah-Amoah et al., 2020).

\section{Conclusion and recommendations}

Based on the results of this research, it can be concluded that there are lots of combinations of influence of different factors, which caused the failure of women-owned SMEs in KigaliRwanda. Those factors are factorised in three groups, namely entrepreneur-related factors, enterprises related factors and environmental factors. Grouping of those factors was based on the PCA technique. The results of this study indicated that the failure of women-owned SMEs results from the entrepreneur inability followed by enterprise incompetence which is both internally controllable factors. The study findings revealed that the unconducive business environment had also contributed to the failure of women-owned SMEs in KigaliRwanda. These findings contribute to the validity of the DCT by explaining how well the internal and external factors must stay glued together to avoid failure among women-owned SMEs, something that was not previously well documented so far.

To overcome these factors that influence SME's failure, the study recommends that women must learn from their mistakes and strive for success by seeking advice from experts before and during the establishment of a business and whenever problems occur before they get worse. This paper, therefore, constitutes a point of reference for other women-owned SMEs in other countries and should be turned into a formal growth strategy by any women-owned SMEs in whichever sector. The government should put much effort into designing a permanent education plan for building the capacity of women entrepreneurs so that they can get a chance to manage and develop their businesses sustainably.

Future research should focus on a comparative analysis of unsuccessful and successful women entrepreneurs to tackle the issue of failure to get a balanced view of the issue. Also, future studies should focus on studying which sector is the most affected by a failure between industrial and service sectors. The developed framework of failure of newly owned women SMEs should be validated in other cultural settings to provide evidence concerning the robustness of the developed framework.

\section{References}

Abdul, O.E. (2018), "Entrepreneurial skill and growth of small and medium enterprise (SMEs): a comparative analysis of Nigerian entrepreneurs and minority entrepreneurs in the UK", International Journal of Academic Research in Business and Social Sciences, Vol. 8 No. 5, pp. 28-46.

Abubakar, S. and Junaidu, A.S. (2019), "External environment factors and failure of small and medium enterprises in the Kano metropolis", Asian Journal of Economics and Empirical Research, Vol. 6 No. 2 , pp. 180-185.

Amankwah-Amoah, J. (2016), "An integrative process model of organizational failure", Journal of Business Research, Vol. 69 No. 9, pp. 3388-3397. 
Amankwah-Amoah, J., Khan, Z. and Wood, G. (2020), "COVID-19 and business failure: the paradoxes of experience, scale, and scope for theory and practice", European Management Journal, doi: 10.1016/J.EJ.2020.09.002. retrieved on 22-01-2021.

Arasti, Z. (2011), "An empirical study of the causes of business failure in Iranian context", African Journal of Business Management, Vol. 5 No. 1, pp. 7488-7498.

Barney, J. (1991), "Firm resources and sustained competitive advantage", Journal of Management, Vol. 17 No. 1, pp. 99-120.

Bhole, N. (2020), "Analysis of business model failure of engineering companies and toll to avoid it", Master's Thesis, Aalto University.

Bouazza, A.B., Ardjouman, D. and Abada, O. (2015), "Establishing the factors affecting the growth of small and medium-sized enterprises in Algeria", American International Journal of Social Sciences, Vol. 4 No. 2, pp. 101-121.

Bushe, B. (2019), "The causes and impact of business failure among small and medium enterprises in South Africa", Africa's Public Service Delivery and Performance Review, Vol. 7 No. 1, 1210, doi: 10.4102/apsdpr.v7i1.210.

Chineam, O.B., Ewah, E.B. and Chukwum, N.S. (2020), "Failure and success of entrepreneurs in Nigeria: an empirical review", International Academic Journal of Business School Research, Vol. 6 No. 4, pp. 1-21.

Dento, A. (2020), "Why do most small businesses in Liberia fail", Open Journal of Business and Management, Vol. 8, pp. 1771-1815.

DiScipio, T. (2017), "Worst side effects of bad customer service (and how to avoid them)", Impact, available at: www.impactbnd.com/blog/5-dangerous-side-effects-of-bad-customer-service

European Federation of Accountants (FEE) (2004), “Avoiding business failure: a guide for SMEs”, FEE Guide, Online, available at: www.fee.be

Hair, J.F., Celsi, M., Money, A.H., Samouel, P. and Page, M.J. (2016), Essentials of Business Research Methods, 3rd ed., Sharpe, Armonk, New York, NY.

Hair, J.F., Hult, G.T.M., Ringle, C.M. and Sarstedt, M. (2017), A Primer on Aprtial Least Square Strucutural Equation Modelling (PLS-SEM), 2nd ed., Sage, Thousand Oaks, CA.

Kasema, R. (2020), "The influence of capabilities on the performance of small and medium manufacturing companies in Rwanda", PhD Thesis, The Open University of Tanzania, Tanzania.

Khan, A., Bibi, S., Lyu, J., Garavelli, A.C., Pontrandolfo, P. and Perez Sanchez, M.A. (2020), "Uncovering innovativeness in Spanish tourism firms: the role of transformational leadership, OCB, firm size, and age", Sustainability, Vol. 12 No. 10, pp. 38-89.

Kline, R.N. (2015), Principles and Practive of Structural Equation Modelling, Guildford Publications, New York, NY.

Kücher, A., Mayr, S., Mitter, C., Duller, C. and Feldbaouer-Dürstmuller, B. (2020), "Firm age dynamics and causes of corporate bankruptcy: age dependent explanation for business failure", Review of Managerial Science, Vol. 14 No. 3, pp. 633-661.

Kulkarni, P., Mutkekar, R. and Ingalagi, S. (2020), "Role of strategic management for employee engagement and skill development for start-ups", Vilakshan - XIMB Journal of Management, Vol. 17 No. 1/2, pp. 79-95, doi: 10.1108/XJM-07-2020-0036.

McDonald, S. (2019), "Why customer complaints are good for your business", SuperOffice, available at: www.superoffice.com/blog/customer-complaints-good-for-business/

Mayr, S., Mitter, C. and Aichmayr, A. (2017), "Corporate crisis and sustainable reoganisation: evidence from bankrupty of Austrian SMEs", Journal of Small Business Management, Vol. 55 No. 1, pp. 108-127.

Micelotta, E., Lounsbury, M. and Greenwood, R. (2017), "Pathways of institutional change: an integrative review and research agenda", Journal of Management, Vol. 43 No. 6, pp. 1885-1910.

Milosevic, I., Mihajlovic, I. and Stojanovic, A. (2019), "Dominants factors of SMEs failure-multi-group confirmatory factor analysis", Serbian Journal of Management, Vol. 14 No. 2, pp. 345-360. 
MINICOM, NISR, MIFOTRI, PSF (2017), Small and Medium Enterprises Development Policy in Rwanda, Kigali, Author.

Nangoli, S., Turinawe, D.D., Kituyi, G.M., Kusemererwa, C. and Jaaza, M. (2013), “Towards enhancing business survival and growth rate in LDCs: an exploratory study of the drivers of business failure among SMMEs in Kampala-Uganda”, International Journal of Humanities and Social Science, Vol. 3 No. 8, pp. 284-291.

Navandar, Y.V., Bari, C. and Gaikwad, P.G. (2021), "Failure factors - a comparative study of private and government construction firms", Engineering, Construction and Architectural Management, doi: 10.1108/ECAM-03-2020-0184

Nikolić, N., Jovanović, I., Nikolić, D., Mihajlović, I. and Schulte, P. (2019), "Investigation of the factors influencing SME failure as function of its prevention and fast recovery after failure", Entrepreneurship Research Journal, pp. 1-21, edited by DEGRUYTER, doi: 10.1515/erj-2017-003.

Pallant, J. (2016), SPSS Survival Manual: A Step-by-Step Guide to Data Analysis Using IBM SPSS, 6th ed., McGraw Hill Pearson, Berkshire.

Pallant, J. (2013), SPSS Survival Manual. A Step by Step Guide to Data Analysis Using SPSS, 4th ed., Allen and Unwin, available at: www.allenandunwin.com/spss

Penkova, T.G. (2017), "Principal component analysis and cluster analysis for evaluating the natural and anthropogenic territory safety", Procedia Computer Science, Vol. 112, pp. 99-108.

Rwanda Governance Board (2012), Rwanda Governance Scorecard 2012, Kigali, Author.

Schaefer, P. (2019), "Why small businesses fail: top 7 reasons for start-up failure, business know-how", available at: www.businessknowhow.com/startup/business-failure.htm

Shephered, D.A., Wennberg, K., Suddaby, R. and Wiklund, J. (2019), "What are We explaining? A review and agenda on initiating, engaging, performing, and contextualizing entrepreneurship", Journal of Management, Vol. 45 No. 1, pp. 159-196.

Stoeberl, P., Parker, G. and Joo, S. (1998), "Relationship between organisational change and failure in the wine industry: an event-history analysis", Journal of Management Studies, Vol. 35 No. 4, pp. 547-555.

Tabachnick, B.G. and Fidell, L.S. (2013), Using Multivariate Statistics, Pearson Education Limited, Boston.

Twesige, D., Hategekimana, U., Gasheja, F., Nkubito, E.J. and Hitayezu, I. (2020), "Analysis of causes of business failure in Rwanda: learning from small and medium enterprises (SMEs)", Global Business and Technology Association, Reading's Book, accessed online on 21-01-2021.

Yin, R.K. (2011), Qualitative Research from Start to Finish, The Guilford Press, New York, NY, available at: http://doha.ac.mu/ebooks/research\%20Methods/QualitativeResearch_2011_Robert_Yin.pdf (accessed 28 February 2021).

Yong, A.G. and Pearce, S. (2013), "A beginner's guide to factor analysis: focusing on exploratory factor analysis", Tutorials in Quantitative Methods for Psychology, Vol. 9 No. 2, pp. 79-94.

\section{Further reading}

National Institute of Statistics of Rwanda (NISR) (2018), Establishments Census 2017, Kigali, Author.

\section{Corresponding author}

*Romain Kasema can be contacted at: kasema.romain@yahoo.com

For instructions on how to order reprints of this article, please visit our website:

www.emeraldgrouppublishing.com/licensing/reprints.htm

Or contact us for further details: permissions@emeraldinsight.com 